NASA/TM-2007-214848

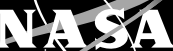

Stress Rupture Life Reliability Measures for Composite Overwrapped Pressure Vessels

Pappu L.N. Murthy

Glenn Research Center, Cleveland, Ohio

John C. Thesken

Ohio Aerospace Institute, Brook Park, Ohio

S. Leigh Phoenix

Cornell University, Ithaca, New York

Lorie Grimes-Ledesma

Jet Propulsion Laboratory, Pasadena, California 


\section{NASA STI Program . . . in Profile}

Since its founding, NASA has been dedicated to the advancement of aeronautics and space science. The NASA Scientific and Technical Information (STI) program plays a key part in helping NASA maintain this important role.

The NASA STI Program operates under the auspices of the Agency Chief Information Officer. It collects, organizes, provides for archiving, and disseminates NASA's STI. The NASA STI program provides access to the NASA Aeronautics and Space Database and its public interface, the NASA Technical Reports Server, thus providing one of the largest collections of aeronautical and space science STI in the world. Results are published in both non-NASA channels and by NASA in the NASA STI Report Series, which includes the following report types:

- TECHNICAL PUBLICATION. Reports of completed research or a major significant phase of research that present the results of NASA programs and include extensive data or theoretical analysis. Includes compilations of significant scientific and technical data and information deemed to be of continuing reference value. NASA counterpart of peer-reviewed formal professional papers but has less stringent limitations on manuscript length and extent of graphic presentations.

- TECHNICAL MEMORANDUM. Scientific and technical findings that are preliminary or of specialized interest, e.g., quick release reports, working papers, and bibliographies that contain minimal annotation. Does not contain extensive analysis.

- CONTRACTOR REPORT. Scientific and technical findings by NASA-sponsored contractors and grantees.
- CONFERENCE PUBLICATION. Collected papers from scientific and technical conferences, symposia, seminars, or other meetings sponsored or cosponsored by NASA.

- SPECIAL PUBLICATION. Scientific, technical, or historical information from NASA programs, projects, and missions, often concerned with subjects having substantial public interest.

- TECHNICAL TRANSLATION. Englishlanguage translations of foreign scientific and technical material pertinent to NASA's mission.

Specialized services also include creating custom thesauri, building customized databases, organizing and publishing research results.

For more information about the NASA STI program, see the following:

- Access the NASA STI program home page at http://www.sti.nasa.gov

- E-mail your question via the Internet to help@sti.nasa.gov

- Fax your question to the NASA STI Help Desk at 301-621-0134

- Telephone the NASA STI Help Desk at 301-621-0390

- Write to: NASA Center for AeroSpace Information (CASI) 7115 Standard Drive Hanover, MD 21076-1320 
NASA/TM-2007-214848

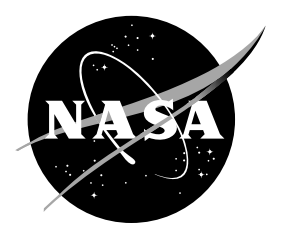

\section{Stress Rupture Life Reliability Measures for Composite Overwrapped Pressure Vessels}

Pappu L.N. Murthy

Glenn Research Center, Cleveland, Ohio

John C. Thesken

Ohio Aerospace Institute, Brook Park, Ohio

S. Leigh Phoenix

Cornell University, Ithaca, New York

Lorie Grimes-Ledesma

Jet Propulsion Laboratory, Pasadena, California

Prepared for the

48th Structures, Structural Dynamics, and Materials (SDM) Conference

sponsored by AIAA, ASME, ASCE, AHS, and ASC

Honolulu, Hawaii, April 23-26, 2007

National Aeronautics and

Space Administration

Glenn Research Center

Cleveland, Ohio 44135 


\section{Acknowledgments}

The authors wish to acknowledge the sponsorship provided by the NASA Engineering Safety Center for the Kevlar and Carbon Independent Technical Assessment

Trade names and trademarks are used in this report for identification only. Their usage does not constitute an official endorsement, either expressed or implied, by the National Aeronautics and Space Administration.

Level of Review: This material has been technically reviewed by technical management.

Available from

NASA Center for Aerospace Information 7115 Standard Drive

Hanover, MD 21076-1320
National Technical Information Service 5285 Port Royal Road Springfield, VA 22161 


\title{
Stress Rupture Life Reliability Measures for Composite Overwrapped Pressure Vessels
}

\author{
Pappu L.N. Murthy \\ National Aeronautics and Space Administration \\ Glenn Research Center \\ Cleveland, Ohio 44135 \\ John C. Thesken \\ Ohio Aerospace Institute \\ Brook Park, Ohio 44142 \\ S. Leigh Phoenix \\ Cornell University \\ Ithaca, New York 14853 \\ Lorie Grimes-Ledesma \\ Jet Propulsion Laboratory \\ Pasadena, California 91109
}

\begin{abstract}
Composite Overwrapped Pressure Vessels (COPVs) are often used for storing pressurant gases onboard spacecraft. Kevlar (DuPont), glass, carbon and other more recent fibers have all been used as overwraps. Due to the fact that overwraps are subjected to sustained loads for an extended period during a mission, stress rupture failure is a major concern. It is therefore important to ascertain the reliability of these vessels by analysis, since the testing of each flight design cannot be completed on a practical time scale. The present paper examines specifically a Weibull statistics based stress rupture model and considers the various uncertainties associated with the model parameters. The paper also examines several reliability estimate measures that would be of use for the purpose of recertification and for qualifying flight worthiness of these vessels. Specifically, deterministic values for a point estimate, mean estimate and 90/95 percent confidence estimates of the reliability are all examined for a typical flight quality vessel under constant stress. The mean and the 90/95 percent confidence estimates are computed using MonteCarlo simulation techniques by assuming distribution statistics of model parameters based also on simulation and on the available data, especially the sample sizes represented in the data. The data for the stress rupture model are obtained from the Lawrence Livermore National Laboratories (LLNL) stress rupture testing program, carried out for the past 35 years. Deterministic as well as probabilistic sensitivities are examined.
\end{abstract}

\section{Nomenclature}

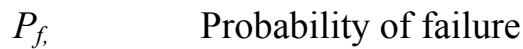

$P_{S} \quad$ Probability of survival

$P\left(t \mid \sigma(),. t_{1}\right) \quad$ Conditional probability of survival

$\sigma_{o p 1,2} \quad$ Stress in fiber at operating present. subscript 1 for past and 2 for current or future. 


$\begin{array}{ll}\sigma_{\text {burst }} & \text { Stress in fiber at burst pressure } \\ \sigma_{\text {tef }} & \text { Fiber strength } \\ t & \text { time in hours } \\ t_{1} & \text { past time in hours } \\ t_{c, \text { ref }} & \text { Some reference time } \\ \rho & \text { Power law coefficient for stress } \\ \beta & \text { Life time shape parameter } \\ \Delta t & \text { Current mission time } \\ g() & \text { limit state function } \\ f_{X} & \text { Joint probability density function } \\ \bar{X} & \text { Vector of random variables } X_{1}, X_{2}, \ldots X_{n}\end{array}$

\section{Introduction}

As with any pressure vessel, risk of failure must be mitigated through an understanding of the failure modes. In particular, metallic pressure vessels are typically designed to exhibit the failure mode called "leak-before-burst". The concept is that leakage results from slow stable crack growth from an initial small flaw, causing a slow, noticeable leak of the contents. This serves as advance warning to retire the vessel before a disastrous burst occurs, releasing stored energy that would likely cause loss of life and significant, possibly catastrophic damage to the spacecraft. COPVs are susceptible to most of the same failure modes as metallic pressure vessels, since the metallic liners have the same mechanical properties, but additional considerations arise from the use of the composite overwrap.

While the metallic liner of a COPV can also exhibit the leak-before-burst failure mode, the composite overwrap is susceptible to other failure modes that are not predictable using such fracture mechanics based prediction tools. Because the composite in a COPV carries a large portion of the pressure load during operation, failure modes associated with the failure of the composite must be considered during the design and operation of these COPVs. In the case of COPVs, there are two primary but related failure modes that can appear after successful qualification of a COPV design: these are stress rupture and loss of structural integrity due to impact damage, which may cause immediate burst failure or may contribute to the stress rupture process. Both of these failure modes can result in the sudden, catastrophic failure of the pressure vessel without the advance warning that is possible with all-metal pressure vessels. A COPV that fails due to the stress rupture failure mode will burst suddenly and with no warning leading to catastrophic consequences such as loss of a vehicle and the crew.

Stress rupture life testing for Kevlar has been performed primarily by Lawrence Livermore National Laboratories (LLNL) and Cornell University with additional Kevlar material characterization contributions from the Y12 Plant at Oak Ridge National Laboratory and Sandia National Laboratories. These tests have consisted of single-fiber, fiber-bundle, resin impregnated strand (or tow tests), and small COPVs testing at several fixed stress levels (refs. 1 to 4 ).

Although models based on data from LLNL, Cornell, and DOE are available in the literature, they are neither directly comparable nor applicable to any other COPV designs that are used on spacecraft. Changes have to be made to account for the load carrying effects of the liner, the effects of strength variations between different spools used to overwrap the COPVs, volume fraction effects of the matrix and compensation for differences in ultimate burst strength of the composite due to differences in pressurization rate between the spacecraft COPVs and the small COPVs tested by LLNL. In addition, corrections to account for Kevlar creep relaxation need to be made.

During the last 3 years there have been two independent technical assessment activities for reassessing the safety of Kevlar and Carbon fiber COPVs on board spacecraft; sponsored by the NASA 
Engineering Safety Center (NESC) (refs. 1 and 2). The work reported here pertains to stress rupture life reliability models discussed in detail in the aforementioned references.

\section{Stress Rupture Life Reliability: Phoenix Model}

It is customary to utilize a Weibull statistics based approach to fit stress rupture life data, and this was done with the original LLNL test data. There are a number of models that exist with some variations, and this is discussed in a separate paper (ref. 5). For the current discussion the Phoenix model is used. The Phoenix model has been developed over the past 27 years and is well documented in the literature (refs. 6 and 7). It is based on a Weibull distribution framework for strength and lifetime with the embodiment of a power law to describe damage in a composite versus stress level. Derivation of the model is available in references where the power-law in stress level (with temperature dependence) is derived from thermally activated chain scission using a Morse potential as a model (ref. 8). The model parameters are based on the LLNL epoxy-impregnated strand and pressure vessel data. In the simplest setting of constant stress applied quickly and maintained over a long time period, the basic equation for the model is below:

$$
P(t, \sigma)=1-\exp \left[-\left\{\left(\frac{t}{t_{c, r e f}}\right)\left(\frac{\sigma_{o p}}{\sigma_{\text {burst }}}\right)^{\rho}\right\}^{\beta}\right]
$$

where $P(t, \sigma)$ represents the probability of failure at time $t$ subjected to applied stress $\sigma$. In the above equation the quantity $\left(\sigma_{\mathrm{op}} / \sigma_{\text {burst }}\right)$ is the ratio of the nominal fiber stress at operating pressure to the nominal fiber stress at burst pressure (called the fiber stress ratio), $t$ is time, $t_{c, r e f}$ is a reference time, $\rho$ is the power law exponent, and $\beta$ is the Weibull shape parameter for lifetime. The fiber stress ratio may be established either by using simple netting analysis in combination with thin shell mechanics or via a detailed finite element analysis. The complete details pertaining to stress ratio calculations as well as the above equation are available in reference 1 . The value for $\sigma_{\text {burst }}$ is determined from the flight COPV burst test data accounting for pressurization rate differences between flight COPVs and the COPVs tested by LLNL (ref. 1). The model is shown for a fixed fiber stress level over time, but for more general time histories a memory integral is used to accumulate damage (similar to Miner's rule for fatigue) at varying stress levels. Also, at very high fiber stress levels a second quantity within square brackets and of similar structure to the first must also be included with a leading minus sign as well (i.e., in a weakest damage mechanism framework). This second quantity has different parameter values, especially a much higher $\rho$ value, and applies to times on the order of 100 hours or less, whereas the parameter values we consider apply to much longer times.

Based on the Phoenix model, a series of reliability quantile curves can be developed for use in design that allow estimation of the lifetime for a chosen quantile. Figure 1 shows the stress rupture life curves for the Phoenix model. This approach can be used by choosing an appropriate combination of stress ratio and lifetime to ensure a desired reliability during the design of a COPV. Analysis based on this approach is employed currently by COPV manufacturers.

Also indicated in figure 1 are data from the original LLNL experiments on small Kevlar COPVs for stress rupture life. The four horizontal lines indicate the failure times in hours of vessels that failed in stress rupture at different stress ratio levels. The number of vessels that failed in stress rupture at each of these stress ratios is $39,24,18$, and 23 out of about 25 to 50 vessels that were held at each stress ratio. The actual data points indicating times to failure in hours is not shown in the above chart. Only the range of values is indicated by the horizontal lines at different stress ratio levels. Further details can be found in reference 1 . No failures were noted at the lowest stress ratio, 0.446 by the time the experiments were stopped and the program had ended. Substantial scatter exists in stress rupture failure lifetimes (almost three orders of magnitude) as seen in the figure. 


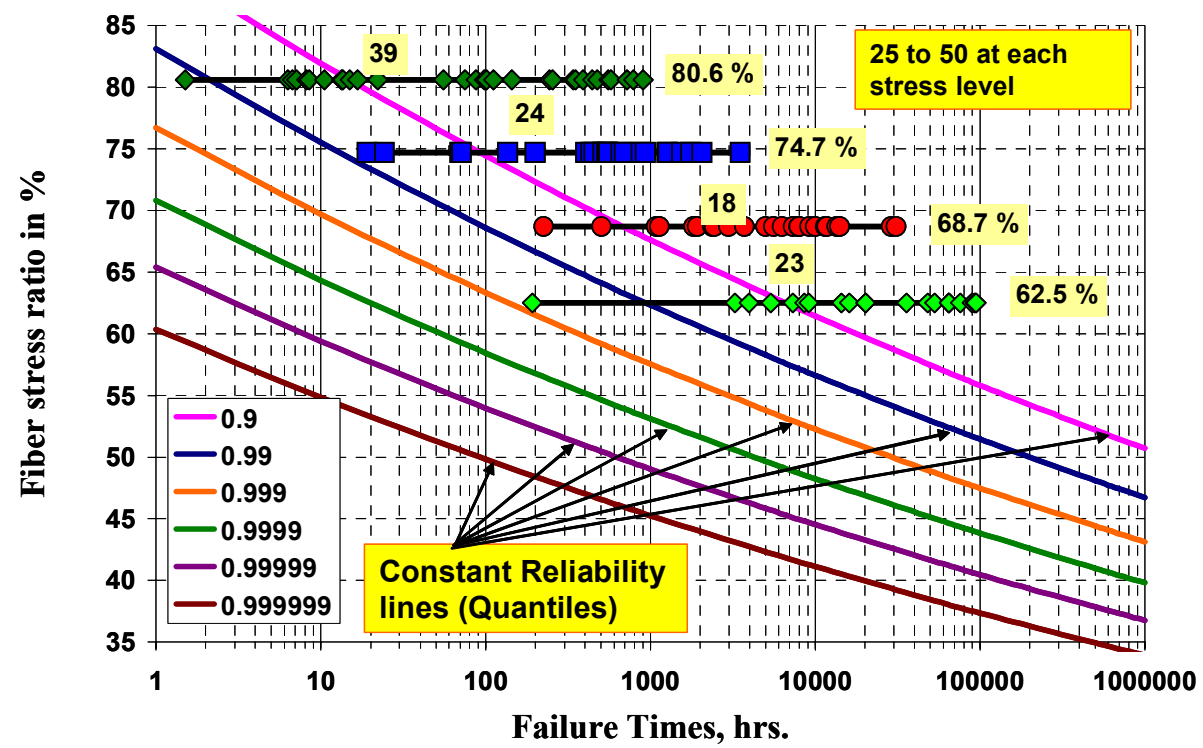

Figure 1.-Stress rupture life reliability quantile curves based on Phoenix model for Kevlar COPVs.

\section{Conditional Probability of Survival}

For recertification purposes of COPVs that have been under successful operation for a prolonged time, however, a conditional probability approach needs to be used (in essence ruling out unusually short lived vessels within the population since none actually occurred). In this approach, at any reference time all successful history prior to this instant is considered in the analysis and credit is taken of this successful past history in the computation of future probability of survival. The conditional failure probability equation for the Phoenix model given in equation (1), can be easily derived with the application of Bayes Theorem (ref. 9) as shown below:

$$
P\left(t \mid \sigma(\cdot), t_{1}\right)=1-\exp \left[-\left\{\left(\frac{t_{1}}{t_{c, r e f}}\right)\left(\frac{\sigma_{o p 1}}{\sigma_{r e f}}\right)^{\rho}+\frac{\Delta t}{t_{c, r e f}}\left(\frac{\sigma_{o p 2}}{\sigma_{r e f}}\right)^{\rho}\right\}^{\beta}+\left\{\frac{t_{1}}{t_{c, r e f}}\left(\frac{\sigma_{o p 1}}{\sigma_{r e f}}\right)^{\rho}\right\}^{\beta}\right]
$$

where $P\left(t \mid \sigma(),. t_{1}\right)$ represents the probability of failure at time $t$, given survival with stress history $\sigma($.$) to$ time $t_{1}$. In this equation, two new terms appear, one for a second, new, stress level and another to account for past history at a previous stress level. The second stress level is introduced to account for any procedural or operational changes to be made for the future missions (such as lowering operational pressure) in order to improve reliability estimates.

As an illustration of the above equation a sample problem is chosen where the reliability is computed for two different operating stress ratios (S.R.) 0.575 and 0.45 . The past survival history amounts to 3743 hours and current mission time is 100 hours. The parameter $\rho$ is taken as $24, \beta$ is taken as 1.2 and $t_{c, r e f}$ is taken as 0.5457 hours. With a ratio of 0.575 , the calculated reliability is 0.9998 while it is 0.9999999 when a ratio of 0.45 is used. If we had been operating the vessel at 0.575 during the entire history of 3743 hours and decided to reduce the ratio to 0.45 for future missions in order to improve the survival probability the result is 0.9999996 . An interesting observation is that it is the future mission hours at a specified stress ratio that is most important in determining the survival probability. Past history has only a minimal effect in this formulation. 


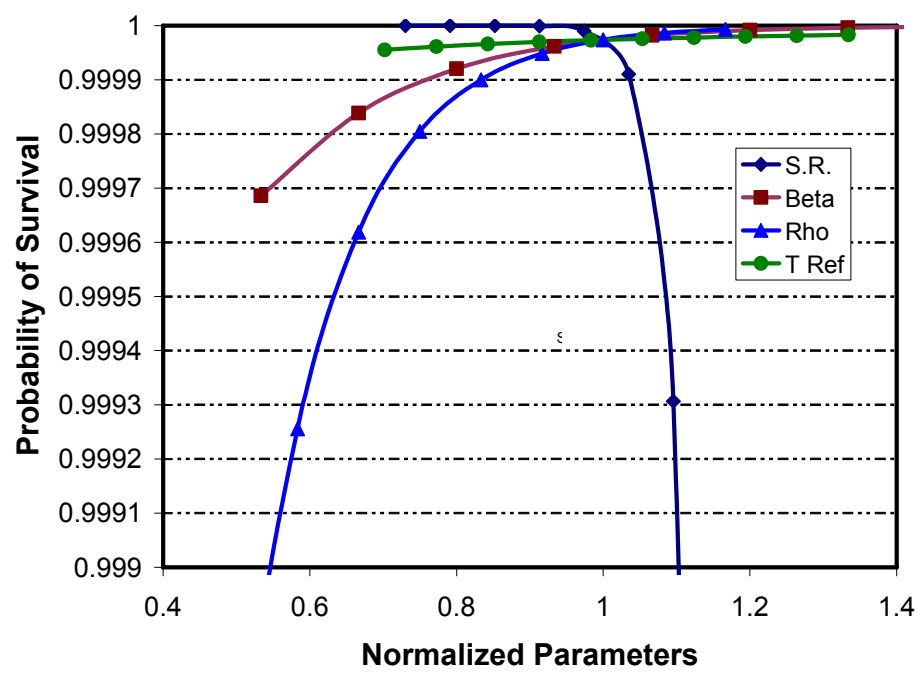

Figure 2.-Sensitivity of the conditional probability of survival to various normalized stress rupture life estimation parameters. In the legend shown S.R. represents stress ratio, Beta represents $\beta$, Rho represents $\rho$, and T Ref represents $t_{c, \text { ref. }}$

The sensitivity of the conditional probability of survival to various stress rupture life parameters of interest is shown in figure 2. Each variable is normalized with respect to the point value (nominal values chosen for the parameters) and is varied one at a time from 0.4 to 1.4. In the example the nominal values chosen are S.R. $=0.575, \rho=24, \beta=1.2$, and $t_{c, \text { ref }}=0.5457$. From figure 2 , it is clear that the conditional survival probability is most sensitive to variables stress ratio and the power law coefficient $\rho$, while it is fairly insensitive to the values of $t_{c, \text { ref }}$ and $\beta$.

\section{Probability of Survival for a System of COPVs}

Stress rupture failure of a COPV has a catastrophic implication of loss of vehicle and crew. The importance, of accurate reliability estimation for each COPV as well as the system of COPVs as a unit cannot be overemphasized. In addition, while computing the reliabilities, one must consider that there are a number of vessels on board a typical spacecraft at various pressures and age and therefore one has to account for all this to arrive at a system level probability of survival which implies survival of every vessel for this duration of mission. In the following section typical calculations are shown for a system of 24 vessels grouped into 5 different sub-systems. Survival of the entire system of vessels in a mission is crucial to successful mission.

\section{Computation of System Level Survival Probability}

For the collective system of vessels the chance for failure of any one of the vessels is derived using the "rare event probability approximation" by the following:

$$
P_{f}=\sum_{i=1}^{n}\left\{1-P_{S}^{i}\right\}
$$

where $P_{f}$ is the chance of any one of the vessels failing due to stress rupture during a mission and $P_{S}$ is the probability of survival of a specific vessel. The above equation is sufficiently accurate for $P_{f} \ll 1$ (rare event probability approximation). The probability of survival $P_{S}$ for a system of vessels is given by

$$
P_{S}=1-P_{f}
$$


The probabilities of failure and survival for individual vessels as well as the system of vessels as a unit are computed for a 24 vessel COPV system and details are shown in table 1.

\begin{tabular}{|c|c|c|c|c|c|c|c|}
\hline $\begin{array}{l}\text { COPV } \\
\text { Sub- } \\
\text { System }\end{array}$ & $\begin{array}{l}\text { Past } \\
\text { Accumulated } \\
\text { Time } \mathrm{t} 1 \\
\text { (Hours) }\end{array}$ & \begin{tabular}{|l} 
Current \\
Estimated \\
Mission \\
Time \\
(Hours) \\
\end{tabular} & $\begin{array}{l}\text { No of } \\
\text { vessels }\end{array}$ & \begin{tabular}{|l} 
Past OP \\
Stress \\
Ratio
\end{tabular} & \begin{tabular}{|l} 
Proposed \\
Mission \\
Stress \\
Ratio \\
\end{tabular} & $\begin{array}{l}\text { Conditional } \\
\text { Probability } \\
\text { of Survival }\end{array}$ & $\begin{array}{l}\text { Conditional } \\
\text { Mission } \\
\text { Probability } \\
\text { of Failure }\end{array}$ \\
\hline$A-1$ & 3743 & 100 & 1 & 0.575 & 0.575 & 0.99984546 & 0.0001545 \\
\hline A-2 & 3431 & 100 & 1 & 0.575 & 0.575 & 0.99984809 & 0.0001519 \\
\hline B 1-2 & 6254 & 195 & $\overline{2}$ & 0.515 & 0.515 & 0.99998602 & 0.0000280 \\
\hline B 3-4 & 5875 & 195 & 2 & 0.515 & 0.515 & 0.99998619 & 0.0000276 \\
\hline B 5-6 & 5686 & 195 & 2 & 0.515 & 0.515 & 0.99998628 & 0.0000274 \\
\hline $\mathrm{C}-1$ & 834 & 24 & 3 & 0.54 & 0.54 & 0.9999955 & 0.0000135 \\
\hline $\mathrm{D}-2$ & 834 & 24 & 7 & 0.47 & 0.47 & 0.99999992 & 0.0000006 \\
\hline $\mathrm{E}-1$ & 73847 & 648 & 1 & 0.445 & 0.445 & 0.99999887 & 0.0000011 \\
\hline $\mathrm{E}-2$ & 73847 & 648 & 1 & 0.445 & 0.445 & 0.99999887 & 0.0000011 \\
\hline E-3 & 73760 & 648 & 1 & 0.445 & 0.445 & 0.99999887 & 0.0000011 \\
\hline $\mathrm{E}-4$ & 65262 & 648 & 1 & 0.445 & 0.445 & 0.9999989 & 0.0000011 \\
\hline E-5 & 61145 & 648 & 1 & 0.445 & 0.445 & 0.99999891 & 0.0000011 \\
\hline E-6 & 21900 & 648 & 1 & 0.445 & 0.445 & 0.99999911 & 0.0000009 \\
\hline \multicolumn{3}{|c|}{ System Probability of Survival } & 24 & & & 0.99958998 & 0.0004100 \\
\hline
\end{tabular}

Vessel subsystems A, B, C, D and E perform various functions, such as Orbit maneuvering, main propulsion, environmental control and life support, and are generally filled with inert gasses such as Nitrogen and Helium. The details are extremely specific to the type of space craft. In the computations it is assumed that the same operating stress ratios are in effect for the past successful history as well as the future/current missions $\left(\sigma_{o p 1}=\sigma_{o p 2}\right)$. As mentioned earlier, if computed reliability is below a desired threshold then the current mission operating conditions need to be adjusted so that a lower stress ratio is achieved.

\section{Parameter Uncertainties}

In general when dealing with reliability one must assess and account for two types of uncertainties epistemic uncertainty and aleatory uncertainty. Epistemic uncertainty arises due to lack of knowledge, or insufficient data. Such uncertainties can be reduced over time with more experiments and experience. On the other hand aleatory uncertainty is the so called physical variability that is present in almost all the systems and is unlikely to be reducible. Various publications address these two types of uncertainty and the importance of separating and resolving them (refs. 11 and 12).

These uncertainties are especially critical for the COPVs because of the risks and costs involved. Model form or epistemic uncertainty can be reduced by collecting more data and by developing better analytical relationships. Here we attempt to show how the model-form uncertainties affect the reliability estimates via Monte Carlo simulations of the conditional probability of survival.

The conditional probability of survival given by equation (2) is a function of several variables and parameters which have been determined based on limited amounts of data. Furthermore the scatter in failure times as noted in the LLNL data often encompasses two to three orders of magnitude.

Uncertainties in the model parameters therefore will have substantial effects on the computed reliabilities. Consequently, deterministic treatment of various parameters in arriving at a single point probability of survival estimate can not be stated with high confidence so that one must consider the confidence bounds on these estimates. Accordingly the point probability estimate becomes a random variable and hence one needs to bound this with either upper or lower confidence bounds or one sided confidence bounds to account for uncertainty in parameter estimates. An attempt is made to capture these with the Phoenix model and is presented in this section. 
Equation (5) is an expression for probability of survival in a generic form as a function of several pertinent random variables representing uncertainties

$$
P_{S}(\sigma, t)=F\left(\sigma_{r}, t_{r}, \Delta t_{r}, \rho, \beta\right)
$$

where

$$
\begin{gathered}
\sigma_{r}=\frac{\sigma_{1}}{\sigma_{c, r e f}}, \\
t_{r}=\frac{t_{1}}{t_{c, r e f}}, \\
\Delta t_{r}=\frac{\Delta t_{1}}{t_{c, r e f}}
\end{gathered}
$$

The symbols $\rho$ and $\beta$ are the stress power law exponent and the shape factor, respectively. A limit state function (sometimes referred to as performance function) is defined as:

$$
g(\bar{X})=P_{S}(\bar{X})-P_{S 0}
$$

Where $P_{S 0}$ is a particular value of $P_{S}$. The vector $\bar{X}$ represents the various uncertain variables considered in the current problem, and these will have a joint uncertainty distribution $f_{x}$ as we now describe. The limit state function can be an implicit or explicit function of random variables and is divided in such a way that $g(\bar{X})=0$ is a boundary between the region $[g \leq 0]$, which means that a certain level of reliability is not met, and $[g>0]$, which means the reliability is exceeded. It should be noted that since the cumulative distribution function (CDF) of $P_{S}$ at $P_{S 0}$ equals the probability that $[g \leq 0]$. The CDF can be computed by varying $P_{S 0}$ and computing the point probability each time.

The probability that $[g \leq 0]$, is then given by the integral

$$
P[g \leq 0]=\int \ldots \int_{\Omega} f_{X}\left(X_{1}, X_{2}, \ldots . X_{n}\right) d X_{1} d X_{2} . . d X_{n}
$$

in which $f_{X}\left(X_{1}, X_{2}, \ldots, X_{n}\right)$ is the joint probability density function for variables $X_{1}, X_{2} \ldots X_{n}$ and the integration is performed over the region, $\Omega$, where $g \leq 0$. If the random variables are statistically independent, then the joint probability density function can be replaced by individual density functions. This integral can be computed by standard Monte Carlo procedure which is rather straightforward. However, depending upon the number of random variables involved and the level of $P_{S 0}$ sought, this must be repeated thousands of times, to accurately build the response variable's probabilistic characteristics. Although inherently simple, the large number of output sets that must be generated to build the CDF of the output variable, becomes its obvious disadvantage. Furthermore, if the deterministic computation of the response is complicated, requiring a time-consuming analysis (e.g., a large non-linear finite element analysis), then the time required and the computational costs could become prohibitive. These procedures are embedded in the NESSUS (Numerical Evaluation of Stochastic Structures under Stress) computer code (ref. 10), developed by Southwest Research Institute (SWRI). 


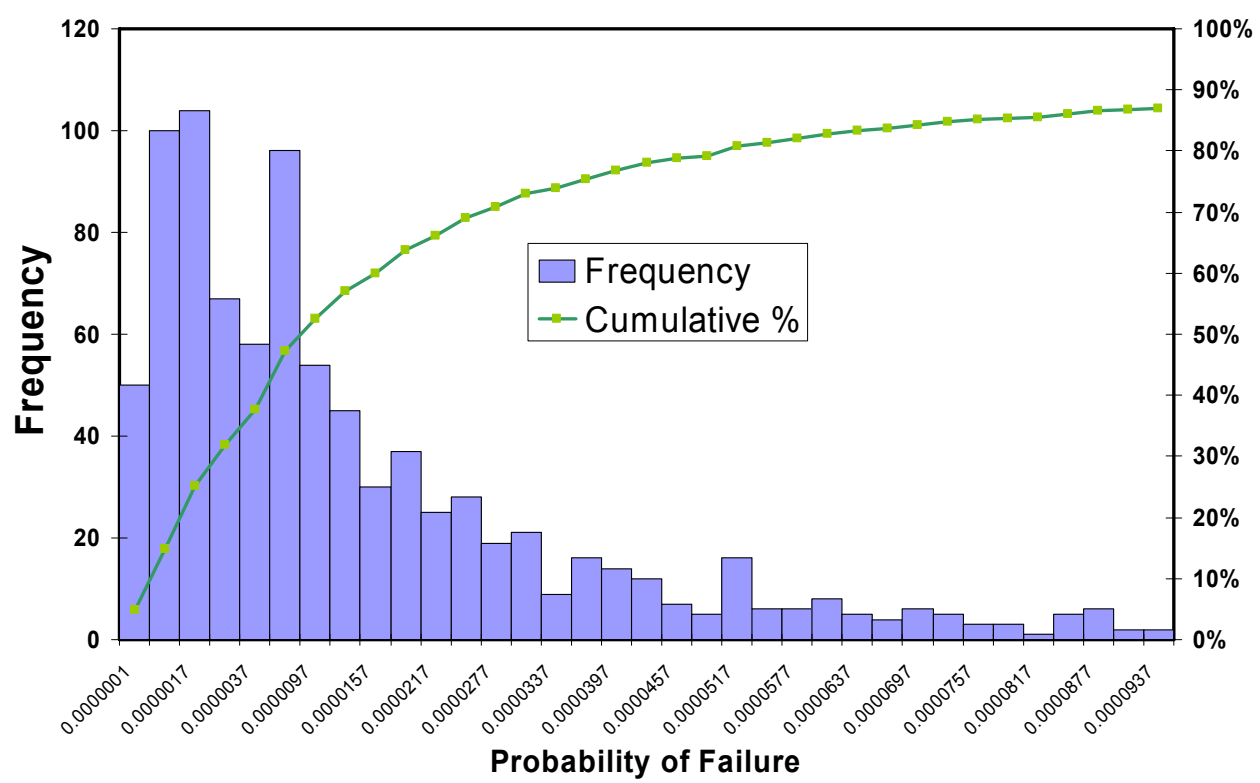

Figure 3.-Probability of failure histogram constructed from 1000 Monte-Carlo simulations for typical Composite Overwrapped Pressure Vessel using the Phoenix Model of conditional probability of failure for Kevlar overwrap.

\section{Point, Mean, and Ninety Five Percent Confidence Estimates for Kevlar Vessels}

In the Phoenix model, values for the parameters $t_{\mathrm{c}, \mathrm{ref}}, \rho$, and $\beta$ are determined based on the LLNL vessel data and are influenced by observations of stress rupture behavior of the strands and single fibers. Due to limited amount of data, (especially, at lower stress ratios) all these parameters must be considered to have uncertainties with respective uncertainty distributions associated with these parameters. One can compute reliability based upon nominal values for these parameters (obtain using maximum likelihood methods applied directly to the lifetime data) and establish the so called point estimate for the reliability. For a fixed set of parameter values the reliability is known exactly through the model. However, such estimates always contain hidden dangers due to the fact that these parameters do have uncertainties associated with them and therefore a probabilistic approach must be adopted to compute mean values of the reliability integrating over the parameter uncertainty distributions. Similarly one can calculate lower confidence bounds on the reliability estimate at some confidence level such as 90 or 95 percent. A typical uncertainty distribution on failure probability, based upon 1000 Monte-Carlo simulations, is shown in figure 3. Here the values for the parameters assumed are $t_{\mathrm{c}, \text { ref }}=0.5457, \rho=24$, and $\beta=1.97$. The uncertainty distributions for these parameters are taken as normal (Gaussian) for all the variables with coefficients of variation representative of the LLNL data sample sizes .

Figure 4 shows a normal probability plot of reliability where the $\mathrm{x}$ axis represents a transformed variable of reliability to indicate basically the "number of nines" for each Monte-Carlo simulation. As shown in the figure the mean probability of survival for this simulation is 0.999993 while the 95 percent confidence value is 0.9998 . A point estimate based on deterministic analysis indicates the probability of survival to be 0.999996 . This is a common situation whereby the mean is less than the point estimate. The cause is that the mean weighs the uncertainty with respect to parameter values that though infrequent can dramatically increase the probability of failure. In other words when an extremely low probability of failure is required and a high probability of failure can result for some parameter combinations, then it is important that these combinations be extremely rare - not just fairly infrequent. In fact, when data sets are small, it is possible for the mean to lie below, the 95 percent confidence value. 


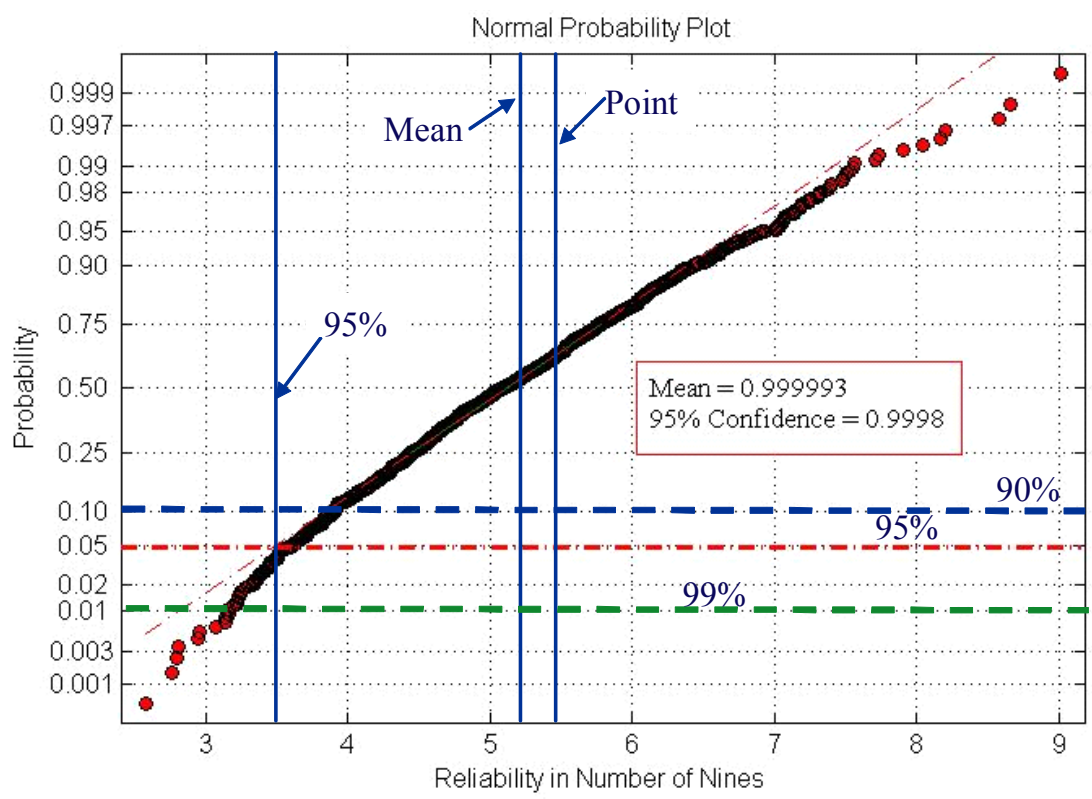

Figure 4.-Normal probability plot of Reliability expressed in terms of number of nines. Reliability in number of nines $=-\log _{10}$ (Probability of failure).

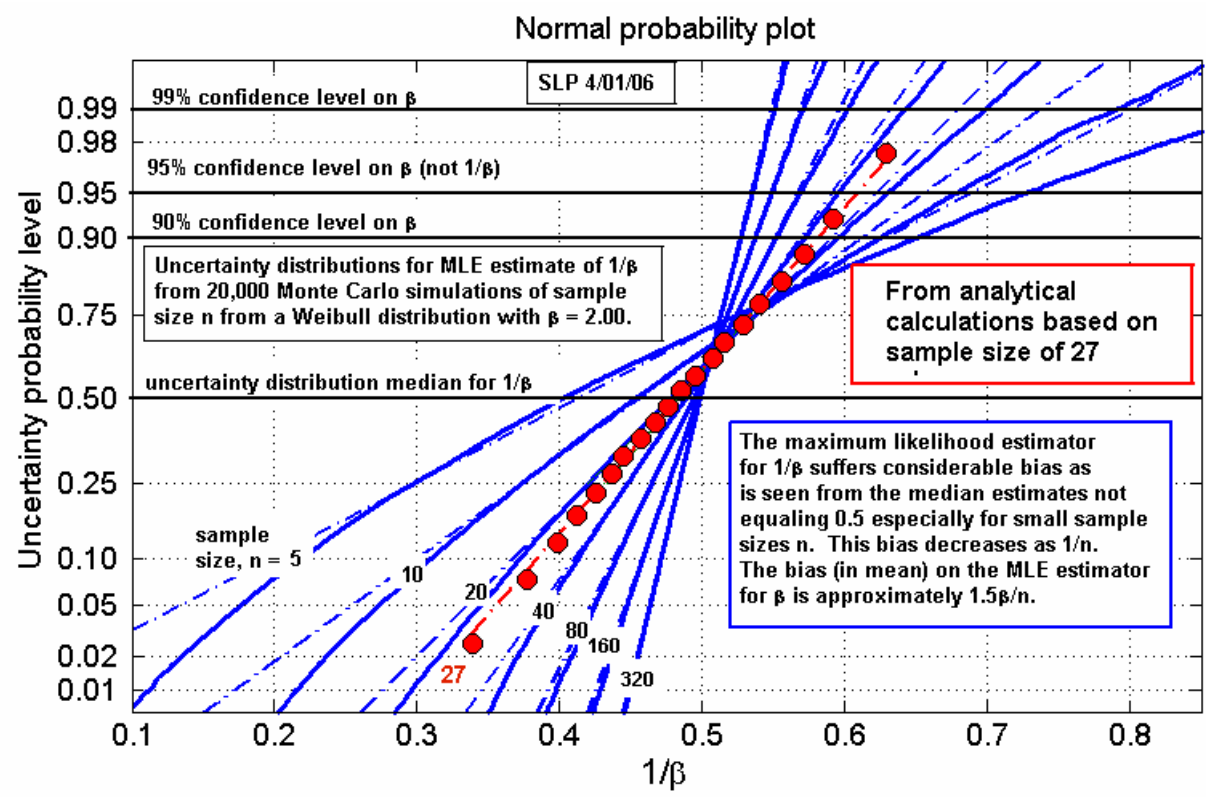

Figure 5.-Monte Carlo simulation results for parameter uncertainty statistics.

\section{Determination of Parameter Uncertainties}

As mentioned before, the model parameters are established utilizing Weibull statistics and Maximum Likelihood Estimates (MLE). However depending upon the available data at each stress level, the uncertainty in the parameters vary and estimates for their distribution mean and standard deviation can be made via Monte Carlo simulation techniques. To illustrate this parameter $\beta$ is chosen and the details are described below.

Figure 5 shows a Monte Carlo simulation of the uncertainty distribution for an MLE of the Weibull shape parameter $\beta$ (actually $1 / \beta$ ) given sample sizes from as low as 5 to as high as 320 . Also shown in the plot are numerical calculations based on the likelihood function for a sample size of 27 , indicated by red 
line with circle symbols. Note that when the sample size is only 10, an MLE estimate can easily be in error by 25 percent either way. This is important because a serious overestimate of reliable lifetime can result simply due to natural variability in samples of size 10, and this should be properly weighed against the probability it could occur. Larger sample sizes, of course, greatly reduce the risk. Similarly the distribution statistics for all the parameters can be established via computational simulation.

\section{Case Study: System Reliability Projections into Future Missions}

The concepts discussed above can be utilized to project individual vessel as well as the system of all the vessels on board reliabilities for future missions. As an example a case study is described here to illustrate how the various metrics for reliability play an important role in determining the future flight reliability for the purpose of recertification of successfully flown system of spacecraft COPVs. The details are provided in table 2.

Table 2 shows various COPV subsystems present on board a typical spacecraft with their accumulated past time in hours at a specific stress ratio (col. 2) and an estimated typical future mission time (col. 3) at the same stress ratio (col. 5). The parameters for the model chosen with uncertainties associated with them are presented in table 3.

TABLE 2.-TYPICAL SPACECRAFT COPV SUB-SYSTEMS AND RELIABILITY ESTIMATIONS

\begin{tabular}{|c|c|c|c|c|c|c|c|c|}
\hline $\begin{array}{l}\text { COPV Sub } \\
\text { System }\end{array}$ & \begin{tabular}{|l|} 
Past \\
Accumulated \\
Time \\
(Hours) \\
\end{tabular} & $\begin{array}{l}\text { Mission } \\
\text { Time } \\
\text { (Hours) }\end{array}$ & $\begin{array}{c}\begin{array}{c}\text { No of } \\
\text { vessels }\end{array} \\
\end{array}$ & Stress Ratio & $\begin{array}{l}\text { Mean Prob. } \\
\text { Survival }\end{array}$ & \begin{tabular}{|l}
$95 \%$ \\
Confidence \\
Prob. \\
Survival \\
\end{tabular} & \begin{tabular}{|l}
$0 \%$ \\
Confidence \\
Prob. \\
Survival \\
\end{tabular} & $\begin{array}{l}\text { Point Prob. } \\
\text { Survival }\end{array}$ \\
\hline $\mathrm{A}-1$ & 4113 & 116 & 1 & 0.575 & 0.99998200 & 0.99991940 & 0.99995650 & 0.99999503 \\
\hline $\mathrm{A}-2$ & 3801 & 116 & 1 & 0.575 & 0.99998300 & 0.99992130 & 0.99995770 & 0.99999526 \\
\hline B 1-2 & 6797 & 132 & 2 & 0.515 & 0.99999900 & 0.99999600 & 0.99999820 & 0.99999989 \\
\hline B 3-4 & 6418 & 132 & 2 & 0.515 & 0.99999900 & 0.99999610 & 0.99999820 & 0.99999989 \\
\hline B 5-6 & 5824 & 27 & 2 & 0.515 & 1.00000000 & 0.99999920 & 0.99999960 & 0.99999998 \\
\hline $\mathrm{C}-1$ & 9212 & 140 & 3 & 0.54 & 0.99999600 & 0.99998110 & 0.99999030 & 0.99999913 \\
\hline D 1-3 & 9514 & 181 & 3 & 0.47 & 1.00000000 & 0.99999960 & 0.99999980 & 0.99999999 \\
\hline D 4-7 & 2006 & 70 & 4 & 0.47 & 1.00000000 & 0.99999990 & 0.99999990 & 1.00000000 \\
\hline E-1 & 75452 & 1468 & 1 & 0.445 & 1.00000000 & 0.99999880 & 0.99999950 & 0.99999998 \\
\hline E-2 & 75452 & 1468 & 1 & 0.445 & 1.00000000 & 0.99999880 & 0.99999950 & 0.99999998 \\
\hline E-3 & 75365 & 1468 & 1 & 0.445 & 1.00000000 & 0.99999880 & 0.99999950 & 0.99999998 \\
\hline E-4 & 66867 & 1468 & 1 & 0.445 & 1.00000000 & 0.99999880 & 0.99999950 & 0.99999998 \\
\hline E-5 & 62750 & 1468 & 1 & 0.445 & 1.00000000 & 0.99999890 & 0.99999950 & 0.99999998 \\
\hline E-6 & 23505 & 1468 & 1 & 0.445 & 1.00000000 & 0.99999910 & 0.99999960 & 0.99999999 \\
\hline \multicolumn{3}{|c|}{ System Probability of Survival } & 24 & & 0.99994900 & 0.99975820 & 0.99987320 & 0.99998708 \\
\hline
\end{tabular}

TABLE 3.-UNCERTAIN PARAMETERS WITH ASSUME DISTRIBUTION STATISTICS

\begin{tabular}{|c|c|c|c|c|}
\hline $\begin{array}{c}\text { Random } \\
\text { Variable }\end{array}$ & Mean & Std. & C.O.V & $\begin{array}{c}\text { Distribution } \\
\text { Type }\end{array}$ \\
\hline oms & 0.9819 & 0.04 & $4.07 \%$ & Weibull \\
\hline $\mathrm{t}$ c,ref & 2.1 & 0.05 & $2.38 \%$ & Normal \\
\hline$\rho$ & 24 & 1.2 & $5.00 \%$ & Normal \\
\hline$\beta$ & 1.6 & 0.26 & $16.25 \%$ & Normal \\
\hline $\mathrm{S}$ & 1 & 0.01 & $1.00 \%$ & Normal \\
\hline
\end{tabular}

For each COPV subsystem a separate Monte-Carlo simulation with 10,000 samples each is conducted with the NESSUS (ref. 10) software and relevant response statistics (mean, point and confidence bounds) are collected from the output to fill in the various columns in table 2 . The point estimate for the COPV system survival is found to be 0.999987 while the mean, 95 and 90 percent estimates are 0.999949 , 0.99976 and 0.99987 , respectively. An interesting point to note is that due to parameter uncertainty, the 

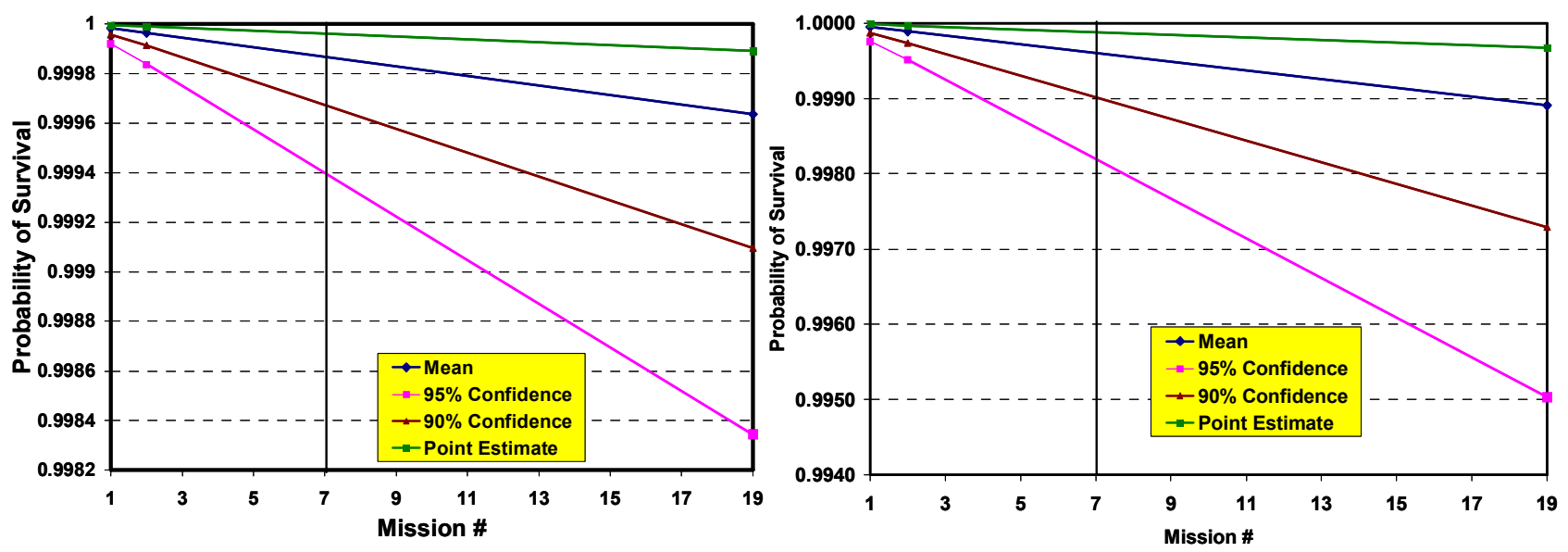

Figure 6.-Various reliability estimate projections for future missions of Vessel A and the total COPV system.

mean and various confidence bounds indicate significantly lower reliabilities compared to the almost six nine reliability indicated by the point estimate.

The simulations are conducted for a single vessel in subsystem A as well as for the collective fleet of $24 \mathrm{COPVs}$ on board a typical spacecraft for a number of future missions, both are shown in figure 6 , the left side figure pertaining to vessel A while the right side figure represents results of the fleet. The number of missions that can be certified for future will depend upon the choice of reliability metric and the required reliability level. These are usually program dependent and must be arrived after carefully examining the total system reliability including all the sub components or assemblies, etc.

\section{Conclusion}

Stress rupture of composite overwraps can cause catastrophic consequences leading to loss of crew and spacecraft and hence the reliability of these vessels during the entire duration of a space program must be carefully examined and assessed. The present paper illustrates via a stress rupture life model proposed originally by Phoenix how the probability of survival of individual as well as a system of vessels on board a typical space craft can be computed systematically. Additionally, various reliability metrics such as point estimates, mean estimates, and 90/95/99 percent one-sided confidence bounds are discussed. Epistemic or model-form uncertainties are assessed by using Monte Carlo Simulation techniques. Such reliability estimates are essential in decision making and certification processes regarding how long (or number of missions) a program should continue before the vessels are either retired or subjected to another recertification process.

\section{References}

1. Shuttle Kevlar Composite Overwrapped Pressure (COPV) for Flight Concern Technical Consultation Report, Vol. I and II, NESC Publication, 2007.

2. Shelf Life Phenomenon and Stress Rupture Life of Carbon/Epoxy Composite Overwrapped Pressure Vessels (COPVs) Technical Consultation Report, Vol. I and II, Dec. 2006.

3. Glaser, R.E., R.L. Moore, and T.T. Chiao, "Life Estimation of an S-Glass/Epoxy Composite under Tensile Loading." Composites Technical Review, Vol. 5, No. 1 (1983): 21-26.

4. Glaser, R.E., R.L. Moore, and T.T. Chiao, "Life Estimation of Aramid/Epoxy Composites under Sustained Tension." Composites Technical Review, Vol. 26 (1984): 26.

5. Lorie Grimes-Ledesma and Pappu L.N. Murthy, "Comparisons of Stress-Rupture Models for COPV Life Prediction." To be presented at the 48th SDM conference, Hawaii, April 23-26, 2007. 
6. Phoenix, S. Leigh and Wu, E.M., "Statistics for The Time Dependent Failure of Kevlar-49/Epoxy Composites: Micromechanical Modeling and Data Interpretation.” IUTAM Symposium on Mechanics of Composite Materials, Pergamon (1983):135.

7. Phoenix, S. Leigh, "Statistical Modeling of the Time and Temperature Dependent Failure of Fibrous Composites." Proceedings of the 9th U.S. National Congress of Applied Mechanics, Book \# H00228, ASME, NY (1982): 219-229.

8. Phoenix, S. Leigh and Tierney, L.J, "A Statistical Model for the Time Dependent Failure of the Unidirectional Composite Materials under Local Elastic Load-Sharing Among Fibers," Engineering Fracture Mechanics, Vol. 18, No. 1, pp. 193-215, 1983.

9. Haldar, A. and Mahadevan, S., Probability, Reliability and Statistical Methods in Engineering Design, Wiley, New York 2000, pp. 25-28.

10. NESSUS (Numerical Evaluation of Stochastic Structures Under Stress). Final NASA Code, New manuals, version 6.2, Southwest Research Institute, San Antonio, TX, 1995.

11. Helton, J.C. and Burmaster, "Treatment of Aleatory and Epistemic Uncertainty in Performance Assessments for Complex Systems," Reliability Engineering and System Safety: Special Issue on Aleatory and Epistemic Uncertainties, 1996: 54: 91-4.

12. Hoffman, F.O. and Hammonds, J.S., "Propagation of Uncertainty in Risk Assessments: The Need to Distinguish Between Uncertainty Due to Lack of Knowledge and Uncertainty Due to Variability," Reliability Engineering and System Safety, 1994: 14: 707-12. 


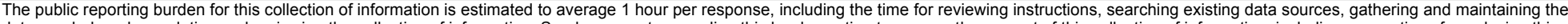

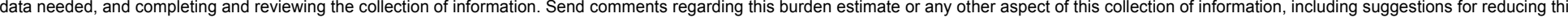

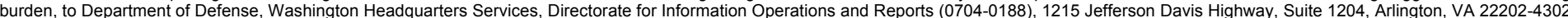

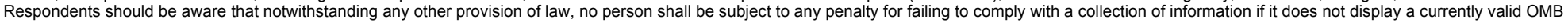
control number.

PLEASE DO NOT RETURN YOUR FORM TO THE ABOVE ADDRESS

\section{REPORT DATE (DD-MM-YYYY) \\ 2. REPORT TYPE \\ 3. DATES COVERED (From - To)}

14-06-2007

\section{TITLE AND SUBTITLE}

Technical Memorandum

Stress Rupture Life Reliability Measures for Composite Overwrapped Pressure

Vessels

\section{5a. CONTRACT NUMBER}

5b. GRANT NUMBER

5c. PROGRAM ELEMENT NUMBER

\section{AUTHOR(S)}

Murthy, Pappu, L.N.; Thesken, John, C.; Phoenix, S., Leigh; Grimes-Ledesma,

Lorie

5d. PROJECT NUMBER

5e. TASK NUMBER

5f. WORK UNIT NUMBER

WBS 843515.02.01.03.04.04.03

\section{PERFORMING ORGANIZATION \\ REPORT NUMBER}

E-16064

National Aeronautics and Space Administration

John H. Glenn Research Center at Lewis Field

Cleveland, Ohio 44135-3191

9. SPONSORING/MONITORING AGENCY NAME(S) AND ADDRESS(ES)

National Aeronautics and Space Administration

Washington, DC 20546-0001

10. SPONSORING/MONITORS
ACRONYM(S)
NASA
11. SPONSORING/MONITORING
REPORT NUMBER
NASA/TM-2007-214848

\section{DISTRIBUTION/AVAILABILITY STATEMENT}

Unclassified-Unlimited

Subject Category: 24

Available electronically at http://gltrs.grc.nasa.gov

This publication is available from the NASA Center for AeroSpace Information, 301-621-0390

\section{SUPPLEMENTARY NOTES}

\section{ABSTRACT}

Composite Overwrapped Pressure Vessels (COPVs) are often used for storing pressurant gases onboard spacecraft. Kevlar (DuPont), glass, carbon and other more recent fibers have all been used as overwraps. Due to the fact that overwraps are subjected to sustained loads for an extended period during a mission, stress rupture failure is a major concern. It is therefore important to ascertain the reliability of these vessels by analysis, since the testing of each flight design cannot be completed on a practical time scale. The present paper examines specifically a Weibull statistics based stress rupture model and considers the various uncertainties associated with the model parameters.

The paper also examines several reliability estimate measures that would be of use for the purpose of recertification and for qualifying flight worthiness of these vessels. Specifically, deterministic values for a point estimate, mean estimate and 90/95 percent confidence estimates of the reliability are all examined for a typical flight quality vessel under constant stress. The mean and the 90/95 percent confidence estimates are computed using Monte-Carlo simulation techniques by assuming distribution statistics of model parameters based also on simulation and on the available data, especially the sample sizes represented in the data. The data for the stress rupture model are obtained from the Lawrence Livermore National Laboratories (LLNL) stress rupture testing program, carried out for the past 35 years. Deterministic as well as probabilistic sensitivities are examined.

\section{SUBJECT TERMS}

Composite overwrapped pressure vessels; Stress rupture; Weibull statistics; Stress rupture life; Liner load sharing; Burst pressure; Operating pressure; Fiber strength; Pressurization rate; Power law; Confidence intervals; Reliability statistics

\begin{tabular}{|l|l|l|l|c|}
\hline \multicolumn{2}{|l|}{ 16. SECURITY CLASSIFICATION OF: } & $\begin{array}{l}\text { 17. LIMITATION OF } \\
\text { ABSTRACT }\end{array}$ & $\begin{array}{c}\text { 18. NUMBER } \\
\text { OF } \\
\text { PAGES }\end{array}$ \\
\cline { 1 - 2 } $\begin{array}{l}\text { a. REPORT } \\
\text { U }\end{array}$ & $\begin{array}{l}\text { b. ABSTRACT } \\
\text { U }\end{array}$ & $\begin{array}{l}\text { c. THIS } \\
\text { PAGE } \\
\text { U }\end{array}$ & & 18 \\
\end{tabular}

19a. NAME OF RESPONSIBLE PERSON
Pappu L.N. Murthy
19b. TELEPHONE NUMBER (include area code)
216-433-3332



